R E VISTA D E E S T U D I O S I I N T E R N A C I O N A L E S

\title{
América Latina y la coordinación de políticas económicas: ¿hacia un Maastricht latinoamericano?
}

\author{
Christian Ghymers*
}

Los acontecimientos de la ultima década han puesto en evidencia que la globalización ha disminuido el fenómeno de las fronteras del "Estado-nación", debilitando las capacidades de acción discrecional de las antoridades nacionales, asi como de los monopolios o grupos sociales internos. Si bien es cierto que hay una amplia convergencia de los economisias y de los politólogos en cuanto a la necesidad de enfrentar esta nueva realidad mediante un progreso en el orden institucional, tanto nacional como internacional, el papel que podria desempeñar el nivel regional como respuesta a la globalización no focaliza mucho la atención. Al contrario, las autoridades tienden a reaccionar en forma aislada, exchusivamente con instrumentos nacionales y sin contemplar ningún tipo de cooperación explicita al nivel regional o de grupo de paises. Los modelos teóricos de los libros acadénicos tampoco consideran la realidad creciente del entorno regional, y consideran a los paises como entidades autónomas, sin asimetrias ni sinergici entre ellos. Por lo tanto, tampoco contemplan las potencialidades de una respuesta regional frente a los defectos de las presiones inestables de la globalización. Estos rasgos ilustran una de las contradicciones caracteristicas de la globalización: el contraste entre los aspectos mundiales del campo económico y la gobernabilidad económica que queda generalmente limitada al marco nacional.

La presente contribución se muestra que la integración regional constituye una palanca potencial para que América Latina logre a menor costo estos progresos institucionales, imprescindibles para adaptar la gobernabilidad de las economias nacionales a la globalización y permitirles sacarle provecho.

"Las opiniones expresadas en este artículo son de exclusiva responsabilidad del autor y pueden no coincidir con las de las organizaciones para las cuales trabaja. 
$\mathrm{U}$ na consecuencia de la globalización durante la década pasada fue el nuevo desarrollo de la integración regional en América Latina. $\mathrm{El}$ acercamiento del mundo externo ha sido un beneficio, al igual que el acercamiento entre economías vecinas. Tanto las estrategias de las empresas multinacionales como las de los exportadores locales tienden a incorporar el entorno regional (proveedores, tamaño del mercado, condiciones macrofinancieras). Cabe destacar que este fenómeno no fue solamente una repuesta al cambio de giro de políticas proteccionistas a una mayor apertura comercial. Fue también un efecto de la convergencia impuesta por la globalización en el campo macroeconómico: las restricciones de financiamiento externo y las presiones de mercados impusieron, con el llamado "Consenso de Washington", el mismo tipo de prioridades y de restricciones en el uso de las políticas macroeconómicas. Al conseguir así un mínimo de convergencia en los parámetros macroeconómicos, llevando a una cierta estabilidad, fue mucho más fácil negociar e implementar acuerdos preferenciales de comercio, tanto en las subregiones como a nivel latinoamericano.

De una cierta manera, la globalización impuso así una convergencia macroeconómica en forma transitoria, o una especie de coordinación implícita, al restringir las opciones disponibles y al hacer más obvios los intereses comunes entre países vecinos.

\section{El entorno regional se incorporó}

por la convergencia que impone la globalización en el campo macroeconómico.

Sin embargo, la globalización, al incrementar la interdependencia entre economías y su comercio intrarregional, ha aumentado al mismo tiempo las externalidades entre las decisiones nacionales de política macroeconómica. Eso significa que no solamente estas crecientes interdependencias tienden a reducir la eficacia de las políticas nacionales (disminuyendo así las posibilidades de acción autónoma de cada país), sino que, además, las condiciones macroeconómicas de una economía dependen crecientemente de las políticas aplicadas por las economías vecinas (externalidades o spillover effects). Mientras más se desarrollan los intercambios comerciales entre dos países vecinos, más impactos recíprocos tienen las orientaciones respectivas de los "policy-mix" macroeconómicos de cada uno. Por esta razón, como también por efecto de contagio y por el carácter gregario y masivo de los mercados financieros globalizados, la percepción de la sostenibilidad financiera de una economía se ha vuelto dependiente de las condiciones macrofinancieras de sus vecinos directos, amplificando sustancialmente las externalidades generadas por las políticas macroeconómicas independientes.

Una prueba inmediata de esta nueva realidad es la existencia de un componente común en las "primas de riesgo" de los 
países de la región, en las evaluaciones de los mercados financieros. Se trata de una correlación entre las fluctuaciones de los spreads financieros de los bonos emitidos por los países de una misma región sin relación con las decisiones y condiciones macroeconómicas propias de cada uno. Este fenómeno indica claramente que la globalización refuerza la importancia de la dimensión regional al otorgar un label común a un grupo de países, por lo bueno o lo malo, es decir, no solamente en caso de crisis sino que durante los períodos de bonanza también.

Fue el caso tanto durante la entrada masiva de capitales del primer período de los años noventa, como durante las crisis financieras y las salidas de fondos que afectaron a las economías emergentes. Sin embargo, este tipo de correlación es más percibido en la fase descendente de la coyuntura regional, cuando su carácter pro-cíclico se manifiesta negativamente, como en el año 2001. El deterioro de las condiciones macroeconómicas y del alza de las primas de riesgos en los países del Mercosur y de sus miembros asociados, durante el período 2000-2001, constituye una elocuente demostración de este fenómeno de "convergencia" macroeconómica forzada que conlleva la globalización. Sin embargo, en esta fase negativa, la convergencia forzada no contribuye a la integración regional sino que, al contrario, tiende a exacerbar los conflictos de intereses entre los países y sus diferentes sectores o grupos.

Además, las autoridades nacionales parecen solamente pensar en reacción y proceso de decisión individuales, sin con- templar ningún tipo de cooperación explícita al nivel regional o sin atreverse a usar los mecanismos ya existentes. Resulta, como lo ilustra el impacto de la crisis argentina, que las depreciaciones de las monedas flotantes (Brasil por ejemplo) responden lógicamente al deterioro de las condiciones financieras de los países cuyo tipo de cambio es fijo (Argentina hasta fin del 2001), empeorándolas en un círculo vicioso potencialmente destructor de la cohesión regional lograda en la fase anterior (el Mercosur).

La depreciación de las
monedas flotantes responde al
deterioro financiero de los
países de cambio fijo.

En este campo regional, también, se llega a la conclusión de que las fuerzas de la globalización "espontánea" no garantizan efectos positivos. Si bien es cierto que las olas globalizadas pueden favorecer la integración regional al poner más énfasis sobre el entorno regional y sus condiciones cuando el ciclo coyuntural es favorable, el carácter inestable y reversible del oleaje externo cuando el ciclo es menos favorable puede ejercer efectos negativos sobre las construcciones regionales. Sin embargo, estos inconvenientes y las crisis que generan, podrían ofrecer una oportunidad para tomar conciencia de la necesidad de superar el presente estado inacabado de la integración regional en América Latina. La globalización ofrece así una herramienta cuyo buen o mal uso depende principalmente de la capaci- 
dad de los países de organizarse en el plano regional.

Esta lectura de los efectos de la globalización sobre el nivel regional pone en evidencia la necesidad de un análisis explícito del proceso de la integración regional, como resultado de una construcción institucionalizada en esta perspectiva más amplia del manejo macroeconómico, que hace falta tanto en la actitud de los gobiernos de la región como en los modelos teóricos dominantes. Los que figuran en los textos académicos tampoco tienen en cuenta la realidad creciente del entorno regional y consideran a los países como entidades autónomas, sin asimetrías ni sinergia entre ellos. Por lo tanto, tampoco contemplan las potencialidades de una respuesta regional a los defectos de las presiones inestables de la globalización y llegan a negar la existencia de la Unión Europea y a prescindir de su experiencia acumulada.

\section{Los modelos teóricos no consideran}

las potencialidades de una respuesta regional a las presiones de la globalización.

La UE es el único ejemplo de construcción regional que, respetando las soberanias nacionales, ha sido exitosa durante un período suficientemente largo. Cabe mencionar que, en la UE, tanto las presiones de los competidores externos como la inestabilidad creciente de las olas financieras durante la naciente globali-zación, crearon las condiciones de una dinámica integradora. La institucio-nalización regional ya existente logró canalizar las reacciones a las presiones generadas por la globalización hacia una repuesta regional metódica y progresiva. La UE pudo así alzarse en la senda de un proceso acumulativo de profundización de su integración: el incremento de la competencia externa de la globalización fomentó la demanda interna, de parte de los actores económicos y políticos, por más integración bajo la forma de una búsqueda de reducción de los costos de transacción provocados por la existencia de fronteras (realización del mercado único), mientras los choques financieros externos, al provocar costosos ataques especulativos entre monedas de sus estados miembros y al poner en riesgo tanto el crecimiento como el funcionamiento del mercado único, incentivaron la búsqueda de una unificación monetaria durable (moneda única). Este proceso se apoyó en una institucionalización de la convergencia macroeconómica mediante una coordinación de las políticas, que focalizó la atención de los mercados financieros y de la opinión pública, gatillando "sanciones de mercados", tanto positivas como negativas.

Siguiendo esta lógica, se vuelve dramáticamente claro que hace falta, tanto en los textos académicos como en la realidad de la toma de decisiones por las autoridades, una dinámica regional parecida en América Latina. El tema de la coordinación de las políticas económicas parece haber desempeñado un papel clave en el éxito europeo. Como no ha podido 
progresar mucho en América Latina, cabe plantear primero el tema de la aplicabilidad del modelo europeo, segundo el tema de los obstáculos a la cooperación regional en $\mathrm{AL}$ y, tercero, poder deslindar una estrategia practicable y adaptada a la zona.

ApliCABILIDAD DEL MODELo EUROPEO A AmÉRICA LATiNA

La pauta que siguió Europa no implica que todo lo que hizo tenga valor universal, y que se debería reproducir en otras regiones para tener éxito en la integración regional. Si bien está claro que la experiencia europea no es transferible como tal a América Latina, quedan sin embargo lecciones importantes que sacar de este conjunto de experimentos a fin de ahorrarse las demoras inútiles o los errores que se cometieron allí. El proceso europeo ha sido muy lento e imperfecto y se desarrolló en un contexto internacional muy diferente. Al lanzar cualquier otro proceso de integración regional es un deber tratar de compararlo con los demás casos.

Sin pretender que el camino europeo sea el único o el mejor, se puede sostener que otras regiones que quieran progresar en su integración podrían sacar provecho de un conocimiento más profundo del caso europeo y de sus métodos.

Ello obedece a que el caso europeo es un experimento que muestra un proceso de "andar a tientas", permitiendo aplicar métodos pragmáticos mientras demostró que otros eran ilusorios en materia de gobemabilidad económica. La integración europea todavía está en vías de implementación. Ella ha sido y sigue siendo larga, penosa, no siempre gloriosa o tan exitosa, y a menudo el progreso resultó en crisis. Este proceso constituye una experiencia útil para los economistas, los científicos políticos y, sobre todo los responsables políticos. Incluso, a pesar de las importantes diferencias entre los casos de las diferentes sub-regiones de AL y de Europa, el método europeo, respetuoso de las soberanías nacionales, puede ser a priori candidato para los casos de AL, que tampoco pretende formar, por ahora, estados federales.

\section{Las regiones que quieran avanzar en la integración deberían conocer más a fondo el caso europeo.}

Lo importante que se debe tener claro es que de ninguna manera se puede importar un resultado, pero sí se puede importar un método para lanzar un proceso propio por grupos de países. La integración regional es necesariamente un proceso endógeno a cada subregión, que es muy diferente a través de América Latina. Este proceso requiere un trabajo colegiado de los responsables políticos y de los expertos técnicos latinoamericanos. Sólo ellos pueden hacerse cargo de lanzar el ejercicio de intercambios que puede llegar a la definición de fórmulas adecuadas a cada subregión.

El análisis de la aplicabilidad o no del modelo europeo constituye un punto de partida concreto y eficiente, y en eso los 
expertos europeos así como de otras regiones pueden ser útiles.

Es necesario enfatizar el punto clave: no se trata de reproducir el camino que trazó Europa, con sus sucesivas etapas de integración comercial, con la unión aduanera primero, después en el campo de las políticas económicas con el mercado único y la unión económica y, al fin, la coronación del primer pilar de la Unión Europea con la moneda única.

La razón viene primero del contexto económico internacional radicalmente distinto de lo que fue en los decenios de 1950 y 1960. En Europa, la integración mediante la unión arancelaria fue establecida en un contexto de crecimiento alto con gran estabilidad monetaria y financiera, sin movilidad alta de capital (en los sesenta), $y$ en un proceso de fuerte consolidación institucional (instituciones y legislación comunitarias, políticas comunes). La vuelta a la convertibilidad de las divisas nacionales en un mismo patrón de tipos de cambio fijos, con pocos movimientos de capitales del sistema de Bretton Woods, permitió asegurar una convergencia obligada y una disciplina automática de las políticas macroeconómicas. Así, se enganchó un proceso de construcción progresiva del área comercial hacia lo financiero y lo monetario antes de tocar las áreas más políticas con los pilares segundo y tercero de la Unión Europea. Del caso europeo se impuso como "obvia" una pauta, presentando a la integración como algo que empieza en el ámbito comercial mucho antes de invadir al campo macro-monetario, y que conlleva una ineludible transferencia progresiva de competencias del ni- vel nacional hacia lo supranacional, como si fuera una ley natural de la historia.

La integración se planteó como un proceso que empieza en el ámbito comercial antes de invadir el campo macro-monetario.

Sin embargo, esta presentación es errónea por dos razones.

1. Se trata de una lectura histórica que es superficial porque no da cuenta de la alta prioridad que se atribuyó a la estabilización macro-monetaria, que fue incluso anterior a los acuerdos comerciales.

2. Corresponde a un pasado cuyos rasgos no se van a reproducir. Aplicando una lectura más económica, y tomando en cuenta, con las dimensiones monetarias y financieras, las grandes tendencias de la globalización que se desarrollaron simultáneamente y que han modificado totalmente el entorno, se llega a reconocer que el camino europeo fue en parte contingente. La pauta que siguió Europa ya no puede reproducirse tal cual en otras regiones, porque el mundo ha cambiado significativamente.

Hoy en día, el proceso latinoamericano de integración se produce en una situación radicalmente distinta, en la cual la estabilidad financiera y de los tipos de cambio no tiene la misma garantía, enfatizando las diferencias entre las políticas macroeconómicas, mientras que el esfuerzo institucional se mantiene débil, sin órgano específico para tomar iniciativas en nombre de los conjuntos subregionales y para hacerse cargo del interés 
regional. Lo poco que existe descansa exclusivamente en la parte comercial (unión aduanera o zona de libre comercio, sin poder supranacional), y las tentativas o modalidades prácticas para coordinar las demás políticas siguen siendo muy débiles. Así, América Latina se encuentra lanzada en unos nuevos intentos de integración con instrumentos obsoletos: sus modalidades institucionales no corresponden al entorno presente de la globalización que pide la consolidación de los procesos de toma de decisiones en el campo macroeconómico, simultáneamente con los progresos meramente comerciales.

Además de lo anterior, esta desventaja se combina con fuertes asimetrías debidas a las diferencias en el peso relativo de los países participantes, principalmente dada la presencia de una economía gigante para sus vecinos (lo que no es el caso en Europa). En este contexto, el problema de las fluctuaciones de los tipos de cambio intrarregionales -que es siempre crucial en materia de integración regionalresulta aún más fundamental para el éxito de una integración basada en el crecimiento rápido de los flujos del comercio intrarregional. Ahora bien, sucede que en América Latina el grado de inestabilidad macroeconómica, que fue hasta hace poco muy alto en promedio, fue sobre todo muy disperso entre los países, de tal modo que el grado de dolarización ha sido diferente entre las economías de la zona, introduciendo marcadas diferencias estructurales en los sectores financieros. Estas diferencias condicionaron los comportamientos privados y públicos, influyendo en el conjunto de instrumentos de política disponibles: en particular, el papel del tipo de cambio divide en dos campos a las economías latinoamericanas, según el esquema de gestión macroeconómica que aplican. Por un lado están los países más dolarizados, como lo ejemplifica Argentina, donde la paridad con el dólar se volvió tan crucial, que fue ventajoso ligarse las manos y abandonar el uso de la política monetaria para fines internos. Por otra parte, están las economías donde las herramientas monetaria y cambiaria se siguen usando muy activamente, como es el caso de Brasil. Esta diferencia entre los regímenes macroeconómicos había reducido la disponibilidad de instrumentos para una posible coordinación en el ámbito regional y es una fuente potencial de conflictos intrarregionales.

\section{Las diferencias estructurales de los sectores financieros condicionaron el comportamiento privado y público.}

Este breve intento de comparar América Latina y la Unión Europea desde el punto de vista de la integración permite llegar a una doble conclusión importante:

- Hoy en día, el campo macroeconómico debe ser incorporado con la más alta prioridad en los esquemas de integración subregional, dado que condiciona la continuación de la integración comercial (e incluso política) de la región: cuál sería la credibilidad para los operadores económicos, de perseguir solamente acuerdos comerciales entre los socios de una subregión, si los resultados de tales acuer- 
dos pueden contrarrestarse por los efectos de una falta de convergencia con posibles desequilibrios macroeconómicos y consecutivas crisis financieras. Dichos desequilibrios crean costosos riesgos de contagio y de reacciones contrarias a la integración regional, obstaculizando la aplicación de los acuerdos.

- Dentro del campo macroeconómico y en cualquier intento de cooperación o coordinación, los tipos de cambio desempeñan un papel clave, dado que permiten apuntar al tema de la convergencia de las políticas macroeconómicas nacionales. Ofrecen una oportunidad concreta para discutir en forma conjunta las políticas internas de cada país de una subregión. La experiencia europea, acumulada sobre todo en este proceso de estabilización de los tipos de cambio mediante el SME y después con la UEM, permite alcanzar unas conclusiones operacionales sobre los límites y alcances de la coordinación entre autoridades soberanas, así como acerca del carácter imprescindible de un mínimo de cooperación macroeconómica para que la integración regional sea exitosa.

La necesidad de mejorar la compatibilidad de las políticas de los socios autónomos de una subregión, que pretenden integrarse, es independiente del hecho de tener o no un proyecto de moneda común. La coordinación regional resulta de la exigencia de ser creíble cuando se pretende construir un mercado único para ser competitivo en un mundo globalizado. Eso fue cierto también adentro de la UE, y sigue siéndolo para los Estados miembros de la UE que no adoptaron el euro, como por el momento Inglaterra, Suecia y Dinamarca, pero que participan plenamente en los ejercicios de coordinación y en los programas de convergencia de la UE.

\section{Para ser competitivo en un} mundo globalizado, la construcción
de un mercado único exige
coordinación regional.

La coordinación es imprescindible tanto para los países que mantienen monedas propias, a fin de que las fluctuaciones de los tipos de cambio cumplan su función fundamental sin entorpecer la integración y al mercado único, como para los que comparten una misma moneda. En este último caso, el grado de coordinación tiene que ser más alto y más sancionado institucionalmente, dado que los riesgos del free riding son mayores y menos sancionados por los mercados.

En ambos casos, los países de una misma subregión tienen interés directo en construir conjuntamente un esquema de coordinación regional para mejorar la transparencia de sus esfuerzos macroeconómicos y asegurar la credibilidad de las políticas decididas.

Un caso particular es el de la dolarización. Para los países dolarizados, es imprescindible disponer de un marco institucional específico que garantice un gran rigor y transparencia presupuestaria a fin de disponer de un instrumento flexible para compensar la pérdida de la autonomía de la política monetaria y cambiaria. Es obvio que este marco sería más eficaz y creíble si se decidiera a nivel re- 
gional. Es lo que hizo falta, y sigue siendo el caso, con la crisis argentina.

Las diferencias entre los regímenes cambiarios condicionan el tipo de coordinación factible al reducir efectivamente la disponibilidad de instrumentos para una posible coordinación en el ámbito regional. Sin embargo no la impide sino que, al contrario, la fuente potencial de conflictos intrarregionales que crearía su ausencia la hace aún más necesaria y urgente.

\section{Las diferencias entre los regímenes}

cambiarios reducen la disponibilidad de instrumentos para lograr la coordinación regional.

Por esta razón, es imprescindible que las políticas nacionales sean más convergentes al perseguir las mismas metas de estabilidad de los precios internos y de presupuestos saneados o equilibrados. En estas condiciones, las fluctuaciones de los tipos de cambio entre los socios de una misma región serían más suaves y tenderían a cumplir sus tareas básicas sin entorpecer la integración comercial.

Cualesquiera sean los regímenes de tipos de cambio que elijan las autoridades de una región, sería poco creíble que los operadores económicos y los mercados financieros pretendieran seguir con un proyecto de integración regional, sin avanzar concretamente en una cooperación macroeconómica que abarque los tipos de cambio. Fue eso lo que llevó a Europa hacia la EMU y al euro, con un mecanismo institucionalizado de coordinación de las políticas nacionales. ¿Por qué no ha sido posible en América Latina?

\section{LOS OBSTÁCULOS MAYORES A LA COOPERACIÓN ENTRE LOS PAÍSES DE AMÉRICA LATINA}

No parece racional que cada país prefiera seguir por su camino propio. Es una opción que resulta más costosa a nivel del grupo regional, exponiendo más la región a la inestabilidad de la globalización e impidiéndole sacar un mejor provecho de los aspectos positivos del fenómeno. Conviene entender las razones universales por las cuales se subestiman los caracteres regionales que comparten los países y las externalidades que generan.

Desde el punto de vista teórico, se ha podido establecer, casi como una evidencia, que un comportamiento cooperativo de responsables nacionales cuyas economías están relacionadas lleva a un equilibrio superior para el conjunto de países. Sin embargo, en el plano operacional, no se ha podido solucionar el problema concreto de que, en el mundo real, las incertidumbres sobre los efectos y los comportamientos de los demás países obstaculizan fuertemente la aplicabilidad concreta del principio cooperativo. Basta mencionar que las asimetrías entre economías, así como también las diferencias de percepción en cuanto al funcionamiento de la economía (el modelo subyacente y la evaluación de la posición cíclica) y los objetivos políticos ("ponderaciones" en las funciones objetivas de los responsa- 
bles nacionales), hacen muy difícil identificar la distribución individual de las ganancias de la coordinación. De hecho, no sirve establecer que un conjunto de países pueda llegar a una situación mejor a nivel global cuando las prioridades de los responsables de las políticas se fijan y son sancionadas solamente en función de sus resultados a nivel nacional y no en términos de resultados colectivos, cuya distribución de ganancias es incierta o se desconoce de antemano.

\section{La incertidumbre acerca del} comportamiento de los demás países dificulta la aplicación del principio cooperativo.

Lo anterior desemboca en una típica situación que la teoría subrayó de manera muy pedagógica con el famoso dilema del prisionero. Éste nos muestra que en caso de riesgo de pérdidas individuales por los responsables, al participar en el juego, la racionalidad individual de los poderes soberanos los lleva necesariamente a escoger estrategias no-cooperativas. Eso resulta costoso para todos. Un importante fundamento del dilema radica en la falta de oportunidad de cooperación (o "colusión", para usar los términos de la teoría de los juegos del dilema) entre las administraciones públicas a cargo.

Los países latinoamericanos no escapan de este universal dilema que afecta a la cooperación internacional por el hecho de depender de las decisiones descentralizadas y soberanas de los gobiernos nacionales: aunque todos perciben que cier- tas acciones conjuntas llevarían a resultados económicos mejores para el grupo de países involucrados, una serie de inhibiciones -perfectamente racionales, según criterios de cada uno a nivel nacionallleva a una falta de cooperación y a resultados menores para el conjunto, pero no necesariamente para cada país en forma separada. Además de dificultades de tipo más técnico (diferencias estructurales, disparidades de niveles de ingreso y otras), los responsables políticos no se atreven a tomar nuevas iniciativas a raíz de la acción de un conjunto de incertidumbres: dificultad de evaluar de antemano la distribución por países de los efectos, desconfianza de las reacciones de los otros países, falta de consenso sobre la evaluación de la situación y las medidas óptimas que sería conveniente adoptar, temor de ligarse las manos con los vecinos y de ser objeto de críticas políticas en su propio escenario electoral (culto de la soberanía), fragilidad institucional nacional y regional $o$, incluso, inexistencia de instituciones regionales adecuadas o de un arbitraje creíble.

Por otro lado, un factor favorable a una salida del dilema en América Latina viene del grado creciente de visibilidad de las interdependencias entre economías cercanas, combinado con la percepción de costos derivados de la falta de verdaderos mercados regionales y de las divisiones frente a países grandes, bloques de terceros países o mercados financieros globalizados. Fue precisamente este tipo de consideración y de presión externa lo que permitió a Europa salir de su propio "dilema del prisionero". 
UN CAMINO PARA SALIR DEL DILEMA DEL PRISIONERO EN AMÉRICA LATINA.

En el caso de Europa, la solución fue muy lenta y resultó de la consideración de los tipos de cambio "como un asunto de interés común". Eso llevó a una gestión de los tipos de cambio mediante el SME que, merced a la cesta de monedas llamada ECU, imponía un proceso colegiado de decisión de las paridades de cada una de las monedas nacionales. La dificultad del proceso y su carácter conflictivo llevaron a los Estados miembros a monitorear los determinantes "domésti$\cos ^{\prime \prime}$ de los tipos de cambio de sus socios regionales, es decir, las políticas nacionales del vecino, cuyas divergencias se traducían en presiones especulativas y cambios de paridades. Como se trataba de un proceso permanente (un juego continuo), la sucesión de rondas de negociaciones o de contactos en el tiempo (multi-period or dynamic games) permitió un aprendizaje mutuo entre responsables. Estrategias de respuesta entre jugadores se desarrollaron y se incorporaron en los comportamientos de cada uno (tit-for-tat). De esta manera aparecieron esquemas de cooperación evolutiva. Por definición, si aparece un comportamiento cooperativo, se sale de las condiciones que fundamentaban el empate individual y el dilema mismo.

Pero Europa tenía desde el inicio una estructura institucional adecuada: por un lado, un motor neutro con la Comisión, cuya tarea era tomar iniciativas e intentar fórmulas, lo que generó un "andar-a-tientas" que se autocorregía; por el otro, el campo económico y monetario disponía de un colegio de expertos especializados que reunía a puertas cerradas (mensualmente por lo menos) a los responsables técnicos de las políticas macroeconómicas nacionales. Este grupo de altos expertos (designados "a título personal" y con estabilidad garantizada, que elegía a su propio presidente y fijaba sus propias reglas), permitió la emergencia progresiva de una confianza mutua y de una cultura comunitaria. Se trataba del "comité monetario" (hoy en día es el Comité económico y financiero), compuesto de dos miembros por país, uno de ellos el director del Tesoro y el otro un responsable de los mercados de divisas del Banco Central nacional, más dos macroeconomistas de la dirección general de economía y finanzas de la Comisión Europea, así como un tercero que actuaba como secretario permanente de apoyo (organización y difusión de los trabajos e intercambios entre miembros).

\section{La estructura institucional de la Unión Europea permitió que surgieran confianza mutua y cultura comunitaria.}

En América Latina, existe una notoria falta de comunicaciones regulares entre expertos económicos que no sean vistas como "negociación diplomática". A partir del diagnóstico de un obstáculo por incertidumbre (dilema del prisionero), reforzado por el carácter formal de los contactos entre administraciones de la misma región, la solución requiere de crear más contactos directos e informales entre macroeconomistas. Éstos, a1 
trabajar juntos pueden reducir las incertidumbres, identificar sus divergencias y dar a esos contactos un carácter meramente informal para que los intercambios sean libres y sólo técnicos, sin cálculo negociador.

Se trata de fomentar el conocimiento mutuo y la comunicación directa entre administraciones nacionales por subregión de integración (Comunidad Andina, Mercosur, MCCA, Caricom). Es muy importante que no consistan sólo en procesos diplomáticos o contactos ministeriales oficiales. Por lo tanto, esta comunicación debe ser "multinivel" y no limitarse como lo es, generalmente, a la preparación o la toma de decisiones. Los contactos deben ampliarse y abarcar trabajos en común y reflexiones conjuntas, en forma simultánea en varios niveles jerárquicos según el propósito, reservando los canales oficiales existentes para la agenda oficial y las negociaciones (ministros) o la toma de decisiones según los procesos formales. Hacen falta trabajos, que los expertos trabajen mancomunadamente sin pretender llegar a decisiones sino para mejorar el conocimiento mutuo, liberar así los intercambios y trabajos técnicos de la coyuntura política y de la agenda oficial y, sobre todo, lograr la creación de nexos personales. Eso permite escapar de la prudencia paralizante que resulta del carácter de negociación oficial que se da en los contactos entre administraciones o instituciones de distintos países. Cuando la comunicación internacional pasa a través de este prisma reductor, se activa la lógica del dilema del prisionero, al quedarse en una lógica jerárquica de política interna.
Se pierden oportunidades de mejorar el conocimiento de la realidad, todo se reduce a la agenda oficial de negociación. Por lo tanto, se avanza a la velocidad del más lento y la lógica de cooperación queda dominada por los altibajos de las políticas internas, sus altos riesgos de enfrentamiento entre vecinos y un errado temor a perder poder en beneficio del nivel regional.

Si los especialistas trabajan juntos, puede evitarse la prudencia paralizante de las negociaciones oficiales.

Cuando los contactos son regulares y menos formales se crean más rápidamente nexos personales y los expertos pueden tomar iniciativas de cooperación efectiva en su propios campos. Se genera una "dinámica de grupo" con una emulación entre los participantes, que compiten para valorizar su papel, su administración y sus conocimientos. Eso induce una nivelación hacia arriba y un esfuerzo creativo. Se logran implementar trabajos de fondo con informaciones novedosas que no hubieran podido programarse, ni a nivel nacional ni en caso de que tuvieran que atravesar todo el proceso de composición de la agenda oficial de las negociaciones regionales formales. Así, al compartir análisis y dificultades, se constituye paulatinamente un "espíritu de cuerpo" entre los expertos macroeconómicos. Esta identidad propia del grupo se convierte en catalizador de la cooperación entre ellos, porque el grupo los ayuda en sus trabajos cotidianos. Los macroeconomistas ganan 
así márgenes de maniobra, contribuyen con más eficacia a la toma de decisiones. Eso permite a cada uno aumentar su peso efectivo en el proceso de decisión interno de política económica. Al tener más contactos externos y trabajos colectivos, se mejoran también los contactos internos dentro de cada administración técnica. Los beneficiarios finales son las autoridades respectivas (ministros), que ganan tanto en información como en motivaciones de sus administraciones, mediante la valorización personal que les otorga su papel en el grupo regional. Se produce así un proceso dinámico que, al mejorar la gobernabilidad de cada país, agiliza también la formación de un consenso regional sobre las medidas que hay que tomar porque se impondrán tarde o temprano.

Además de olvidar que se trata de recuperar los márgenes de maniobra que están ya perdidos a nivel nacional, esta concepción presenta a los organismos regionales como competidores de los gobiernos o administraciones nacionales. Eso alimenta las sensibilidades nacionalistas y agrega al dilema del prisionero una situación de "daño de responsabilidad" (moral hazard), en que a los responsables no les interesa tomar en serio los compromisos regionales y hacer efectiva la integración. Por lo tanto, en esta concepción centralizadora de la integración, que está pasada de moda y equivocada, la agenda de la integración regional no podría progresar mucho debido a un vicio lógico más profundo. Si bien es cierto que la integración regional implica que algunos poderes se traspasan del nivel nacional al nivel regional para recuperar márgenes de ma- niobra a este nivel (por ejemplo, al formar una unión arancelaria o en una unión económica y monetaria), la experiencia europea reciente demostró lo limitado y excepcional de estos campos. Al contrario, el consenso sobre la importancia del concepto de subsidiaridad permitió clarificar la naturaleza de la integración entre naciones soberanas y confortar las soberanías y las atribuciones de los poderes nacionales. Es otro ejemplo para los responsables latinoamericanos de la importancia de analizar bien el caso europeo y sus errores pasados. La tendencia hacia la centralización de las decisiones que adoptaron todos los esquemas integracionistas en el mundo (no sólo en Europa, sino en África y en América Latina; recuérdese el Pacto Andino en su versión inicial) resultó un rotundo fracaso.

\section{El consenso sobre la importancia del concepto de subsidiaridad permitió esclarecer la naturaleza de la integración entre naciones soberanas.}

En el campo de la coordinación de las políticas económicas a nivel regional, este enfoque centralizador se tradujo en el temor de que las responsabilidades de la nación sean sometidas a decisiones de organismos supranacionales carentes de legitimidad política. Este temor ha reforzado el famoso dilema del prisionero, mediante la desconfianza hacia los organismos regionales y la excesiva formalización de los contactos entre gobiernos y adminis- 
traciones nacionales, percibidas en términos de negociaciones. Por lo tanto, se inhibieron los intercambios de información y el conocimiento mutuo.

Es necesario que esta clarificación sea hecha en América Latina, especialmente en el campo macroeconómico y monetario. Si se tiene bien claro que la coordinación macroeconómica no pretende imponer decisiones sino mejorar el proceso nacional de toma de decisiones, el conflicto de intereses no sólo desaparece sino que se transforma en un motor de cooperación al beneficiar directamente a los dirigentes nacionales.

Cada grupo subregional de países (Mercosur, CAN, MCCA, CARICOM) tiene los elementos básicos necesarios para monitorear y organizar un mínimo de debates y cooperación en el campo macroeconómico. El Mercosur creó el GMM (Grupo de Monitoreo Macroeconómico) en junio 2000, que en diciembre de ese año llegó a definir metas comunes de inflación, déficit públicos y deuda. La CAN tiene desde 1998 al Consejo Asesor de ministros de hacienda y presidentes de bancos centrales, que ha propuesto ya la fijación de criterios de topes para inflación, déficit y deuđa pública. Además, se instituyó recientemente (junio del 2001) un Grupo Técnico Permanente (GTP) para preparar el monitoreo de criterios del Consejo Asesor. El Mercado Común Centroamericano tiene desde los años sesenta al Consejo Monetario, que agrupa a los bancos centrales y monitorea criterios comunes.

La existencia de estos dispositivos indica que el proceso deseado para llegar a una cooperación macroeconómica subregional está en marcha. Sin embargo, estos esfuerzos son claramente insuficientes y muy lentos, lo que indica que están bloqueados por el llamado dilema del prisionero, y desembocan en la búsqueda de criterios que no imponen una disciplina común efectiva.

\section{El proceso para llegar a una integración económica subregional está en marcha.}

Para que el dispositivo se transforme en el verdadero proceso anglosajón de checks and balances, que estos países no logran construir por sí mismos, es necesario combinar la competencia entre naciones soberanas con una cooperación de los participantes de las administraciones y bancos centrales nacionales movida por interés propio, según el método pragmático europeo.

Se trata de entender la "economía política regional" que permite implementar una auténtica "subsidiariedad" entre los niveles regional y nacionales: la subregión genera un valor agregado beneficioso para sus miembros, en la medida en que es capaz de definir reglas comunes que incentiven una autodisciplina de parte de cada uno de sus miembros. La economía política de la integración regional europea muestra que los esquemas exitosos son los que actúan en favor de los participantes nacionales. Debe ser el autointerés, tanto de los países individuales como de los representantes de las instituciones participantes, lo que motive y defina el tipo de cooperación entre los 
socios regionales. A nivel regional, no se puede ser tan ingenuo como para pedir que los participantes sacrifiquen sus propias metas o intereses en favor de sus vecinos o de la integración regional. En cambio, puede ofrecer a sus miembros canalizar las potentes fuerzas movilizadas para defenderse de los errores de los socios, al organizar una sana competencia en la que todos respeten reglas consensuadas fijadas en ese plano.

Eso es lo que se llama una cooperación movida por el interés propio de sus participantes, dado que la existencia de un dispositivo de monitoreo colectivo, mediante reglas comunes trasparentes, genera beneficios directos para cada uno de ellos. Las políticas nacionales ganan credibilidad al saberse vigiladas por los ojos críticos de los actores en juego, para asegurar que las acciones de los vecinos no les provoquen daños.

\section{Las políticas nacionales ganan credibilidad cuando se saben vigiladas por los ojos críticos de los actores.}

Este mecanismo de competencia requiere que el ejercicio del monitoreo sea puesto bajo la mira de los economistas, de la prensa especializada y de los mercados financieros, creando así "sanciones" tanto positivas como negativas.

Como se ha indicado, América Latina ya tiene todos los mecanismos institucionales necesarios para poner en marcha un verdadero monitoreo macroeconómico. Lo que le falta es dinamizar sus usos. A este fin, proponemos un plan de acción que apunte a incentivar el uso de estrategias cooperativas al crear procedimientos que hagan más visibles las responsabilidades individuales de cada país y cada actor oficial, y que fomenten el debate abierto. La idea básica es reforzar la visibilidad y la credibilidad del monitoreo oficial mediante un diálogo crítico con los macroeconomistas independientes (discussants). Este proceso de evaluación permanente por los profesionales cuya reputación está en juego exige un mínimo de organización (pero sin cambios institucionales) para llamar la atención y crear presiones de los mercados o de la opinión pública. De este modo, los responsables tienen intereses directos y personales en usar el monitoreo subregional para ganar credibilidad y respaldo, o evitar sanciones de los mercados.

Este plan de acciones pragmáticas supone:

1) Empezar con una declaración de las autoridades superiores de cada subregión sobre el hecho obvio de que "los tipos de cambio y las políticas macroeconómicas son de interés común" de todos los países de la subregión y, por tanto, implican acciones comunes de búsqueda conjunta de un contenido consensual y operacional para este principio básico de la integración regional.

2) Encargar a los grupos técnicos oficiales de monitoreo de cada subregión (los grupos de monitoreo macro, o GMM) la preparación de proposiciones concretas, en especial a tenor de dos orientaciones complementarias: (i) los tipos de cambio de las monedas de cada país miembro 
deben ser objeto del monitoreo conjunto permanente y cada modificación de régimen o de paridades debe ser discutida previamente a puertas cerradas por los expertos nacionales de Hacienda y de los bancos centrales. Para las monedas flotantes o no-fijas, este grupo establece por consenso bandas cambiarias indicativas, en función de las políticas nacionales anunciadas; estas bandas implican, como mínimo, consultas subregionales automáticas cuando los tipos de cambio amenazan con sobrepasar los límites consensuales esperados; (ii) someter los trabajos y resultados de los grupos oficiales de monitoreo a la crítica abierta del debate profesional y público. Para ello, lo más adecuado sería organizar a nivel subregional un foro independiente dirigido por un pequeño "grupo técnico autónomo" (GTA), compuesto por cinco macroeconomistas independientes (de la región o del exterior). Éstos serían seleccionados según criterios de prestigio científico por las autoridades académicas y la prensa especializada, de acuerdo con enfoques objetivos, y se organizarían autónomamente. La subregión les encargaría analizar y dar a conocer su opinión en forma independiente mediante evaluaciones periódicas de las políticas de los países y del monitoreo realizado por el GMM oficial y las decisiones de los consejos ministeriales. Actuarían como consultores a honorarios, sin ser funcionarios permanentes, y sus informes estarían expuestos a la sanción de sus pares y de la prensa internacional especializada. Antes de emitir sus informes técnicos, deberían discutirlos en una reunión con el GMM oficial. Luego, publicarían sus evaluaciones y periódicamente organizarían un foro público para debatirlas y focalizar la atención de los mercados, de la opinión pública y de las instituciones financieras internacionales.

3) Autoestablecer rápidamente unas reglas comunes para la subregión, al desarrollarse estas prácticas de vigilancia mutua acerca de los tipos de cambio y de las políticas que los fundamentan. En materia de tipo de cambio, a fin de ganar credibilidad, será provechoso contemplar posibilidades de acción común en casos predeterminados y según principios claros (por ejemplo, si hay consenso, emitir comunicado común, anunciar metas cambiarias comunes o, incluso, emprender intervenciones concertadas, etc.), cuya práctica podría llevar a contemplar un Sistema Monetario Subregional con bandas obligatorias (estilo SME). Respecto del monitoreo de las políticas, se necesitará la rápida definición consensual de reglas precisas preestablecidas, siendo la primera prioridad establecer criterios cuantitativos, tanto para fijar metas en señal de alerta de insostenibilidad. Esto no significa que los criterios tengan que ser uniformes o idénticos para cada país, sino que implica definir conceptos, métodos y estadísticas comunes y trasparentes, respaldados por el conjunto de países, incluso si se trata de reconocer una especificidad nacional. También será necesario establecer los procedimientos concretos del monitoreo, de su publicidad final y de los posibles incentivos o sanciones. 
Un plan de acciones pragmáticas supone la aplicación de reglas comunes a la vigilancia mutua de los tipos de cambio y las políticas que los fundamentan.

Es importante recalcar que este plan de acción puede implementarse en la práctica a partir de lo existente en cada subregión. Su comienzo no requiere de negociaciones diplomáticas o políticas ni compromisos formales sino sólo iniciarse en el marco de las reuniones ordinarias entre expertos nacionales, para que su dinámica intrínseca prenda en un proceso autovalidado por los incentivos entre responsables. Incluso, el pequeño presupuesto subregional que requiere la creación del grupo de discussants independientes y la animación del debate abierto podría generarse con parte de los recursos disponibles para estudios de política macroeconómica y con apoyo de fundaciones $u$ organismos internacionales. También, la prensa especializada y las instituciones financieras podrían financiar la parte del debate público con sus recursos destinados a publicidad.

La fuerte competencia por el prestigio personal, en la profesión de los economistas, constituye el combustible gratuito de ese motor de progreso que es el debate crítico abierto. Los efectos potenciales en la reputación de las personas servirán de agente autorregulador gratuito del mercado (aparentemente fácil) de las críticas a los gobiernos y bancos centrales, sancionando severamente los errores profesionales.

\section{ConClusión}

América Latina no necesita un "Maastricht formal" importado de Europa, con criterios uniformes de convergencia, sino una aplicación pragmática -adaptada por los responsables macroeconómicos-del método europeo. Éste combina un espíritu de competencia entre países y administraciones nacionales con la cooperación por subregiones de éstos, para establecer los mecanismos de monitoreo por reglas consensuales en condiciones de presión de los mercados. Del funcionamiento conjunto de estos mecanismos podrían nacer sistemas monetarios subregionales con coordinación efectiva de las políticas nacionales.

En este momento, sólo se requiere activar la toma de conciencia por cada participante del valor agregado constituido por el nivel subregional -actualmente incluso el más grande-, que adolece de la ruinosa falta de credibilidad de los distintos países.

La solución es una sola: intentar, sin compromisos formales ni negociaciones políticas previas, fórmulas concretas de monitoreo mutuo trasparente. Éstas no cuestan nada y acarrean los beneficios del "intercambio de buenas prácticas", de incentivos de los encargados de mejorar las políticas y de la credibilidad. Además y sobre todo, esta vía de solución es la de la integración regional duradera, palanca del progreso institucional necesario para el crecimiento sostenible de la región. 